NASA Technical Memorandum 107728

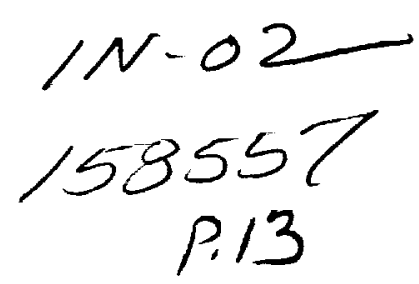

\title{
AN OVERVIEW OF AEROELASTICITY STUDIES FOR THE NATIONAL AERO-SPACE PLANE
}

Rodney H. Ricketts

Thomas E. Noll

Woodrow Whitlow Jr.

Lawrence J. Huttsell

March 1993 NATIONAL AEROSPACE PLANE (NASA)

(NASA-TM-107728) AN OVERVIEW OF

N93-23422 AEROELASTICITY STUDIES FOR THE

Uncl as

63/02

0158557

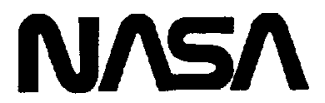

National Aeronautics and

Space Administration

Langley Research Conter

Hampton, Virginia 23665 


.




\title{
AN OVERVIEW OF AEROELASTICITY STUDIES FOR THE NATIONAL AERO-SPACE PLANE
}

\author{
by
}

\author{
Rodney H. Ricketts ${ }^{*}$, Thomas E. Noll ${ }^{* *}$, Woodrow Whitlow, Jr. ${ }^{\dagger}$ \\ NASA Langley Research Center \\ Lawrence J. Huttsell ${ }^{\text {t† }}$ \\ USAF Wright Laboratory
}

\begin{abstract}
The National Aero-Space Plane (NASP), or X-30, is a single-stage-to-orbit vehicle that is designed to takeoff and land on conventional runways. Research in aeroelasticity was conducted by the NASA Langley Research Center and the USAF Wright Laboratory to support the design of a flight vehicle by the national contractor team. This research includes the development of new computational codes for predicting unsteady aerodynamic pressures. In addition, studies were conducted to determine the aerodynamic heating effects on vehicle aeroelasticity and to determine the effects of fuselage flexibility on the stability of the control systems. It also includes the testing of scale models to better understand the aeroelastic behavior of the X-30 and to obtain data for code validation and correlation. This paper presents an overview of the aeroelastic research which has been conducted to support the airframe design.
\end{abstract}

\section{Introduction}

The National Aero-Space Plane (NASP), or X-30, is a single-stage-to-orbit vehicle that is designed to takeoff and land on conventional runways. An artist concept of a NASP vehicle is shown in figure 1 . A vehicle that accomplishes the mission requires a minimum-weight structure that is capable of withstanding large temperature changes. These requirements lead to a vehicle structure that has inherent flexibilities and is susceptible to stiffness reductions due to thermal loads and gradients. These stiffness reductions, in tum, may lead to a degradation in the aeroelastic stability of the vehicle. Beginning in 1987 some experimental and analytical studies were conducted to assess the aeroelastic characteristics of the NASP vehicle and to validate the computational tools that are used in its design.

* Head, Configuration Aeroelasticity Branch, Structural Dynamics Division; Senior Member, AIAA

** Head, Aeroservoelasticity Branch, Structural

Dynamics Division; Associate Fellow, AIAA

$f$ Head, Unsteady Aerodynamics Branch, Structural

Dynamics Division; Senior Member, AIAA

t+ Aerospace Engineer, Aeroelastic Section,

Structures Division; Associate Fellow, AIAA
Initial studies in aeroelasticity of NASP-like vehicles were performed under the Technology Maturation Plan (TMP) and mainly focused on three areas: increasing and validating unsteady aerodynamics and aeroelastic analysis capabilities to meet NASP needs; expanding integrated analysis methodology to include thermal effects and active control technology; and, developing an experimental data base for a better understanding of the aeroelastic response characteristics of NASP-like vehicles. Selected results from efforts in these three areas are presented in figures 2-4 and are described in reference 1.

Beginning in 1991 the research was restructured according to Govemment Work Packages (GWP) and to be performed by government agencies in direct support of the national contractor team which is designing the NASP X30 vehicle. The work that is reported herein was accomplished by the NASA Langley Research Center and the USAF Wright Laboratory. It encompasses both analytical and experimental studies of the complete vehicle, as well as its components, such as lifting surfaces and fuselage panels, to determine and evaluate its flutter characteristics. Furthermore, the work involves development and validation of advanced methods for predicting unsteady aerodynamic forces and aeroservothermoelastic instabilities. An overview of the efforts in each of these areas is presented in this paper. The purposes of the paper are to indicate the scope of the technical work which has been performed in these areas and to introduce the technical papers which present the details of the work in two special sessions on Aero-Space Plane aeroelasticity at the 34th AIAA SDM Conference.

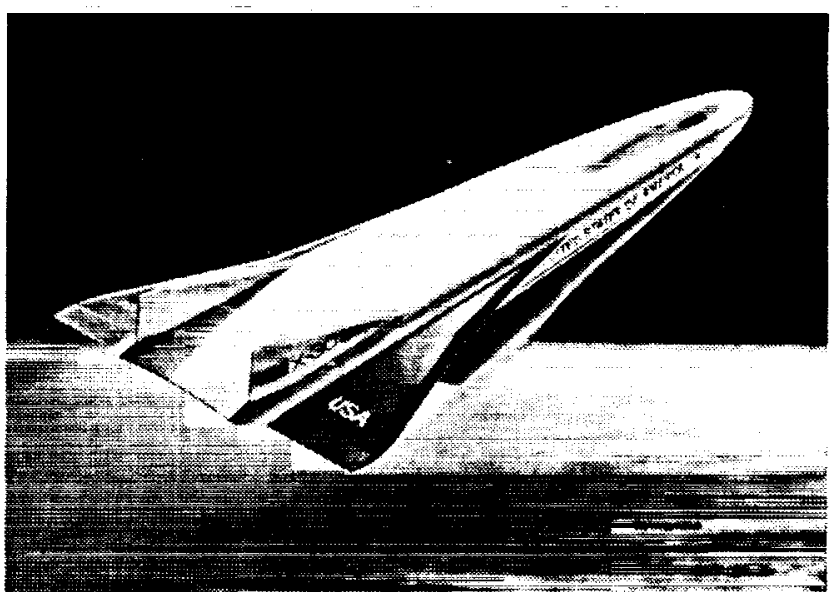

Figure 1. Artist concept of NASP X-30 vehicle. 
-Now FPE finite-volume formulation completed
-FPE method permits use of body-fitted grids

-2D method coded to demonstrate capability

NACA 0012 Airtoil at $M=0.75, \alpha=2^{\circ}$
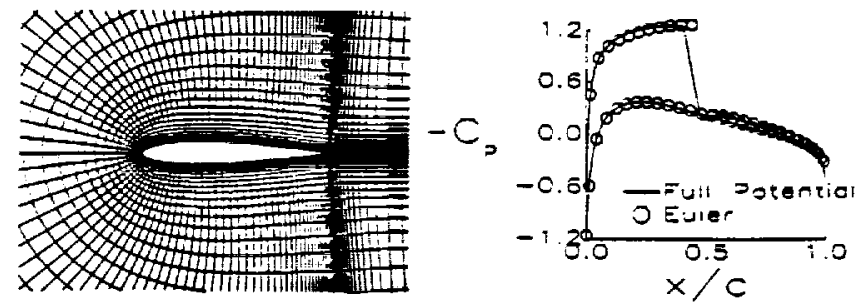

Figure 2. Full potential flow and Euler analysis of NACA0012 airfoil.

\section{Demonstrator Vehicle}

The NASP X-30 vehicle which is shown in figure 1 has a large fuselage with hydrogen-fuel internal tanks, clipped double-delta wings with trailing-edge elevons for roll and pitch control, and vertical fins for lateral stability. For purposes of the GWP studies, this vehicle was modified to include all-moveable clipped delta wings for pitch and roll control. Drawings of the planform and side profile of the modified vehicle, named the Demonstrator Vehicle, are shown in figure 5. A NASTRAN structural finite element model ${ }^{2}$ of this vehicle was developed and used in the studies. It is shown in figure 6. A typical flight trajectory for this vehicle is shown in figure 7 .

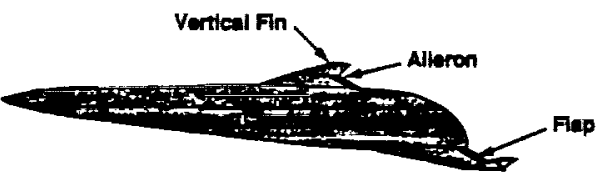

BLPE QUALTYMPROVEMEMI

ELIIIER SUPPAFSSION

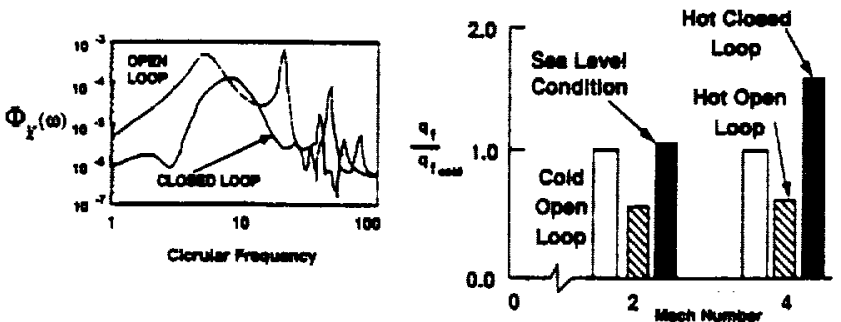

Figure 3. Ride quality and flutter suppression results of a generic NASP design.

\section{Analytical Studies}

Major efforts have been undertaken to develop new and enhanced computational codes for accurate predictions of unsteady aerodynamic loads and effects of thermal heating on the structure. The research in these area are described in this section.
FLUTTER AND DIVERGENCE OF ALL-MOVEABLE DELTA WING DETERMINED

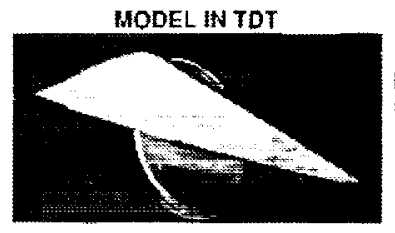

FLUTTER BOUNDARY

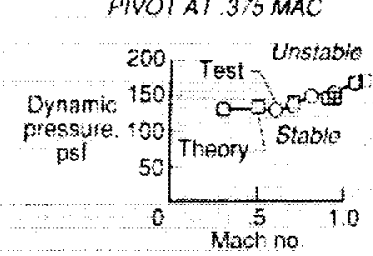

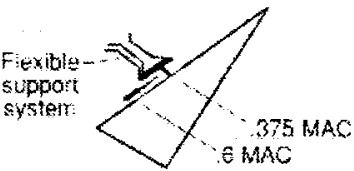

DIVERGENCE PIVOTAT G MAO

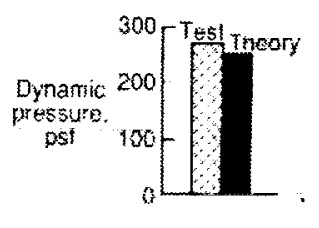

Figure 4. Experimental/analytical results of simple allmoveable wing tests in TDT.

\section{Unsteady aerodynamics}

The unsteady aerodynamics effor has the goal of developing computational methods for unsteady aerodynamic and aeroelastic analyses of the NASP over its flight envelope. This was accomplished by assessing the state-of-the-art codes and by modifying three existing computational fluid dynamics (CFD) codes to allow accurate analysis of NASP-like vehicles. The modified codes are the CAP-TSD (Computational Aeroelasticity Program - Transonic Small Disturbance) aeroelastic analysis code which uses transonic small disturbance (TSD) potential aerodynamics and the CFL3D and ENS3DAE codes which use Euler/Navier-Stokes aerodynamics. The Euler/Navier-Stokes codes provide analysis capabilities for all speed ranges, and CAP-TSD is used for transonic analysis. This section presents an assessment of state-of-the-art codes and a description of the new analysis capabilities which were obtained by modifying CAP-TSD and CFL3D to allow aeroelastic analysis of a NASP-like vehicle. In addition some selected results are presented.
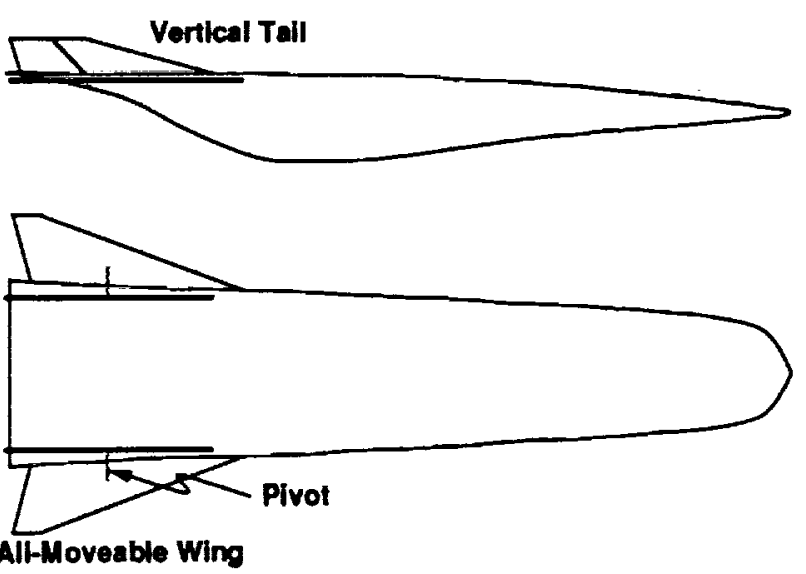

Figure 5. Profile and planform of Demonstrator Vehicle. 
State-of-the-art codes. The NASP vehicle in its ascent trajectory will be required to fly through an extraordinarily large range of Mach number conditions as indicated by the flight profile shown in figure 7 . Therefore, a variety of existing computer codes associated with aeroelastic analyses were assessed. Codes associated with modeling the aerodynamic shape, calculating vehicle surface temperature distributions, developing finite element models with aerodynamic heating effects included, conducting steady, unsteady, and nonlinear aerodynamic analyses, performing linear aeroelastic analyses, and designing and analyzing control systems were considered. These codes, with recommendations on their usefulness in meeting the GWP objectives, are described in reference 3. A summary of the assessment of the aerodynamic codes follows.

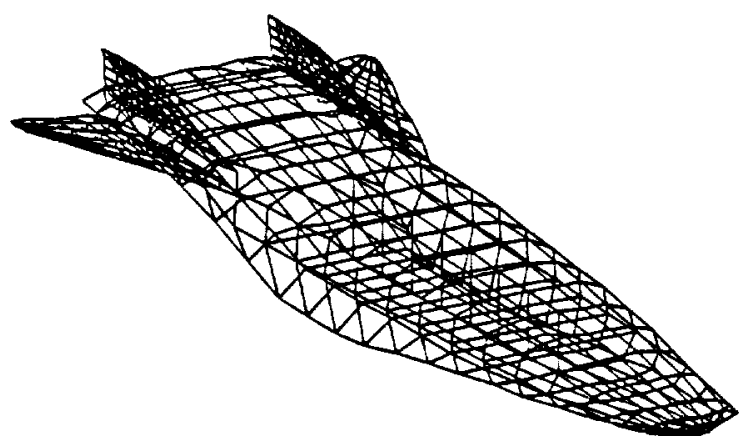

Figure 6. Structural finite element model of NASP Demonstrator Vehicle.

Presently, reliable and accurate linear lifting surface theories exist for predicting unsteady aerodynamic forces and performing flutter analyses for general configurations at subsonic Mach numbers up to about 0.95 and at supersonic Mach numbers from 1.05 to about 3. For Mach numbers from about 3 to 10 , simple linear methods such as Van Dyke's second-order piston theory and Newtonian impact theory can be used to predict the unsteady aerodynamic forces. However, for Mach numbers above 10 , the validity of using these simple methods is questionable because of the presence of severe shock interactions, unusual flow phenomena, and chemically reacting gases. The aerodynamic codes used in this study and their range of applicability are summarized in figure 8.

CAP-TSD. The CAP-TSD code was developed at the NASA Langley Research Center and has been used to predict wing flutter ${ }^{4}$ accurately and to model nearly complete aircraft configurations 5,6 . It can be used for analysis of flight vehicles with an arbitrary number of horizontal lifting surfaces, vertical surfaces, and bodies. The original code only could be used for analysis of vehicles with rigid fuselages and vehicles with vertical surfaces that were rigid and had rectangular planforms. The additions of a flexible, swept, vertical surface capability and a fuselage flexibility were required for aeroelastic analysis of a Demonstrator Vehicle; such a vehicle has a flexible, lifting fuselage and flexible, swept, vertical surfaces.

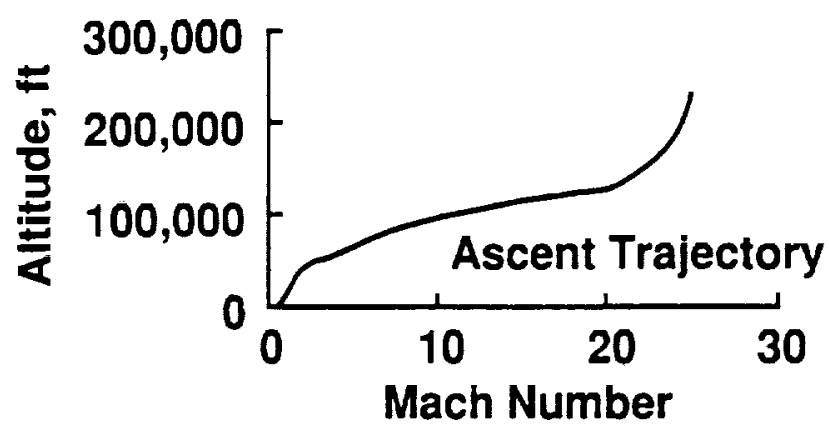

Figure 7. Representative ascent trajectory.

Calculations that demonstrate the capabilities of the CAP-TSD code are presented next. They include calculations for the following configurations: the AGARD T-tail, a slender fuselage, and a NASP vehicle. Figure 9 shows unsteady lifting pressures on the AGARD T-tail for the vertical fin oscillating in twist at $\mathrm{M}=0.8$ and $\mathrm{k}=1.5$. (The T-tail configuration is shown at the upper left of the figure.) Results are shown for three spanwise stations--one on the vertical fin at 65-percent of semispan, one on the horizontal stabilizer near the junction of the fin and stabilizer (five-percent semi-span), and one at 55-percent semi-span of the stabilizer. The unsteady motion produces significant interference effects on the horizontal stabilizer, especially near the fin-tail junction, as shown in the upper right of figure 9. The effects of the vertical fin leadingedge singularity on the solution also can be seen in the pressures at the fin-tail junction. Comparisons with the doublet-lattice aerodynamic method ${ }^{7}$ in the ISAC (Interaction of Structures, Aerodynamics, and Controls) ${ }^{8}$ code show good agreement.

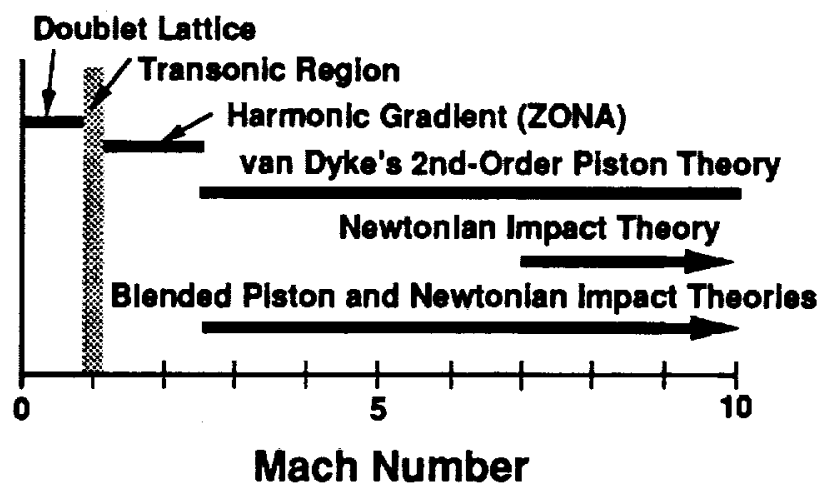

Figure 8. Aerodynamic theories used for flutter calculations. 
Calculations of steady pressures on a slender fuselage with circular cross sections are presented next. Figure 10 shows a comparison of calculated and measured steady surface pressure coefficients $C_{p}$ along the top and bottom of the fuselage for $\mathrm{M}=0.99$ and an angle of attack of $8.4^{\circ}$. For this case a shock wave exists around the fuselage near the 80-percent chord line. The pressures calculated using CAP-TSD show very good agreement with the experimental data from reference 9 .

Figure 11 shows the calculated pressures along the top and bottom centerlines of the NASP fuselage for $\mathrm{M}=$ 0.9 and an angle of attack of 0 degrees. The pressure distribution is relatively smooth along the top of the vehicle, but along the bottom, the pressure distribution shows rapid expansion at the engine inlet and at the aft end of the engine assembly. Surface pressure contours for this case are shown in figure 12 .
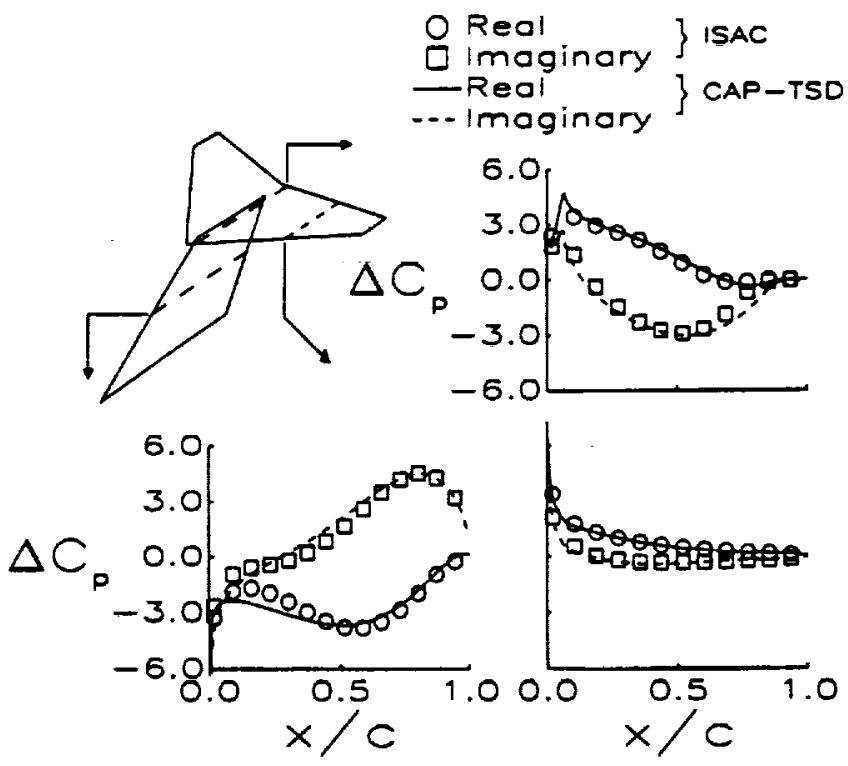

Figure 9. Unsteady pressure distributions on AGARD $T$-tail configuration.

The comparisons of calculations with standard analysis methods and experimental data show that the swept, flexible, vertical surface and flexible fuselage capabilities were formulated and implemented correctly in the CAP-TSD code. This indicates that the modified code is suitable for unsteady aerodynamic and aeroelastic analyses of NASP-like vehicles.

CFL3D. CFL3D is a CFD code that was developed at the NASA Langley Research Center to solve the timedependent Euler and thin-layer Navier-Stokes equations. 10 Its original algorithm contained the necessary metric terms for calculating unsteady flows that required only rigidly translating and rotating meshes that moved without deforming. In time-marching aeroelastic calculations, the mesh must be updated at every time level so that it conforms to the aeroelastically deformed shape of the vehicle. Because the aeroelastic motions may be arbitrary, a general mesh updating procedure is necessary. This procedure which was incorporated into CFL3D is one which models the mesh as a network of springs and solves the static equilibrium equations for this network to determine the new locations of the mesh grid points 11,12 .

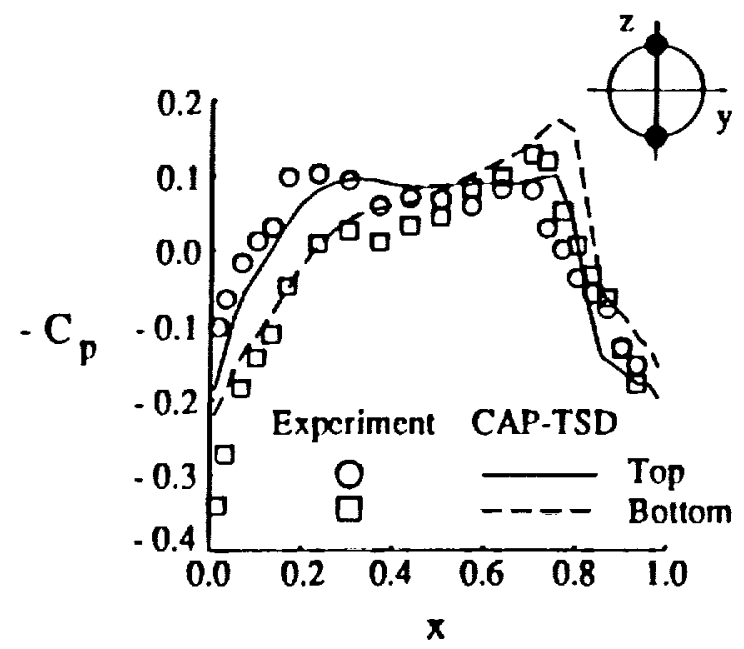

Figure 10. Steady pressure distributions along slender circular fuselage.

The aeroelastic equations of motion which are incorporated within CFL3D are similar to those described in references 4 and 12 . The dynamic equations of motion are formulated in terms of generalized displacements. After exciting the vehicle structure, damping and frequency characteristics of the aeroelastic responses are estimated from the response curves by using the modal identification technique of Bennett and Desmarais ${ }^{13}$. Damping estimates are used to determine zero-damping values (flutter points).

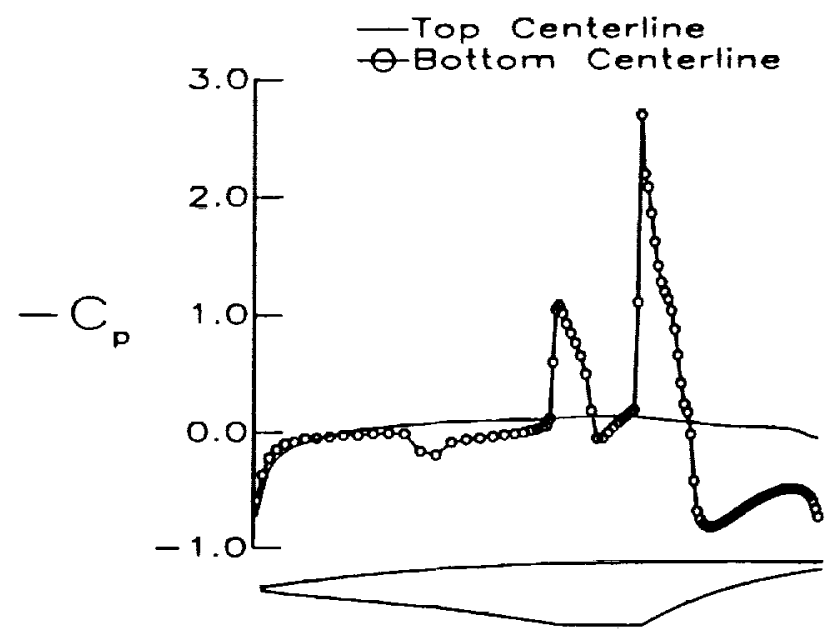

Figure 11. Steady pressures along the centerline of NASP fuselage. 


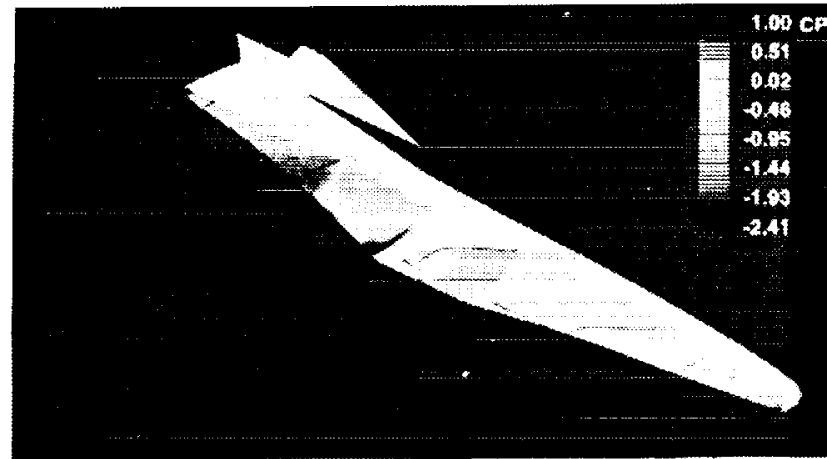

Figure 12. Surface pressure contours on NASP vehicle.

Figure 13 shows the aerodynamic grid and steady pressure contours on a NASP wing calculated using the Euler equations for $M=5, \alpha=2.2^{\circ}$. Figure 14 shows the surface pressure coefficients on the root chord section of the NASP wing undergoing a static aeroelastic pitch deformation of $2.2^{\circ}$ at $M=5$. One calculation is for the wing rotated rigidly, and the other is for the wing deforming in a mode that simulates rigid pitch. The good agreement between the two calculations demonstrates that the deforming grid method, which is necessary for aeroelastic analysis, is working correctly.

The aeroelastic analysis capability of the CFL3D code was demonstrated by calculating the flutter characteristics of the AGARD Wing 445.6, which was tested ${ }^{14}$ in the Transonic Dynamics Tunnel at the NASA Langley Research Center. Figure 15 shows a partial view of the computational grid on the wing surface and symmetry plane. Comparisons of measured and calculated flutter speeds and frequencies are shown in figure 16 (reference 15). The calculations show very good agreement with the measured data for subsonic Mach numbers. At Mach numbers higher than that for which the minimum flutter speed occurs, the calculated flutter speeds and frequencies are significantly higher than the measured values. These characteristics are consistent with those of other inviscidflow flutter analyses of the $\mathbf{4 4 5 . 6}$ wing. The calculations verify the aeroelastic analysis capability of the modified CFL3D code which now can be used for analysis of NASP vehicles.

Additionally, a quasi-steady aerodynamic approach 16 based on small perturbations about the static aeroelastic shape and the use of only steady CFD aerodynamics was developed for performing hypersonic flutter analyses. For this study the CFL3D code ${ }^{17}$ was used. The technique assumes that the vehicle velocity is very high such that the reduced frequency of important flexible vehicle motions is within the quasi-steady range of aerodynamics. Under these conditions, time constants of the unsteady flow are so small that the aerodynamics acting on the vehicle can be assumed to have no memory. The real part of the pressures are obtained from CFD calculations where the grid has been deformed into the structural mode shapes. The imaginary parts of the pressure modes are obtained by simulating the small motions of the mode shapes through the a transpiration boundary condition on the surfaces of the vehicle. By the superposition assumption, the generalized aerodynamic forces computed from the pressure modes can be used to perform linear flutter analyses and aeroservoelastic modeling.
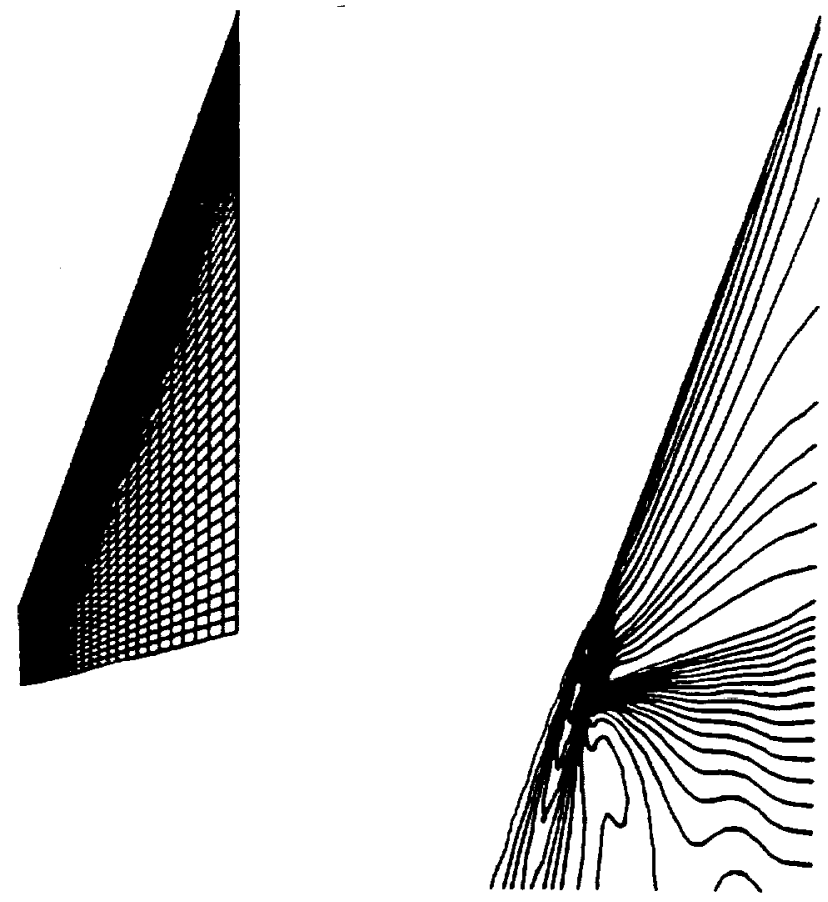

Figure 13. Aerodynamic grid and pressure contours for NASP wing upper surface at $M=5, \alpha=2.2 \mathrm{deg}$.

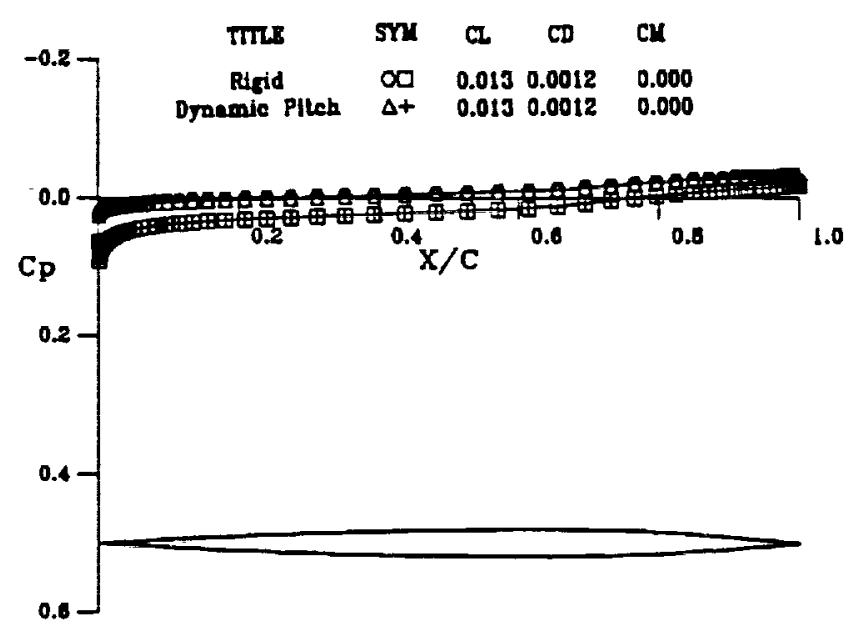

Figure 14. Surface pressures along root chord of NASP wing at $M=5, \alpha=2.2 \mathrm{deg}$.

At hypersonic speeds, the quasi-steady aerodynamic technique can be used to provide more accurate and potentially less conservative flutter predictions than the more common linear unsteady methods. The quasi-steady technique includes the steady nonlinear aerodynamics 
effects and should result in a more realistic flutter sizing of hypersonic vehicles and, possibly, lighter structural weights. And, of course, the technique is much cheaper and faster than using fully unsteady CFD aerodynamics for aeroelastic calculations.

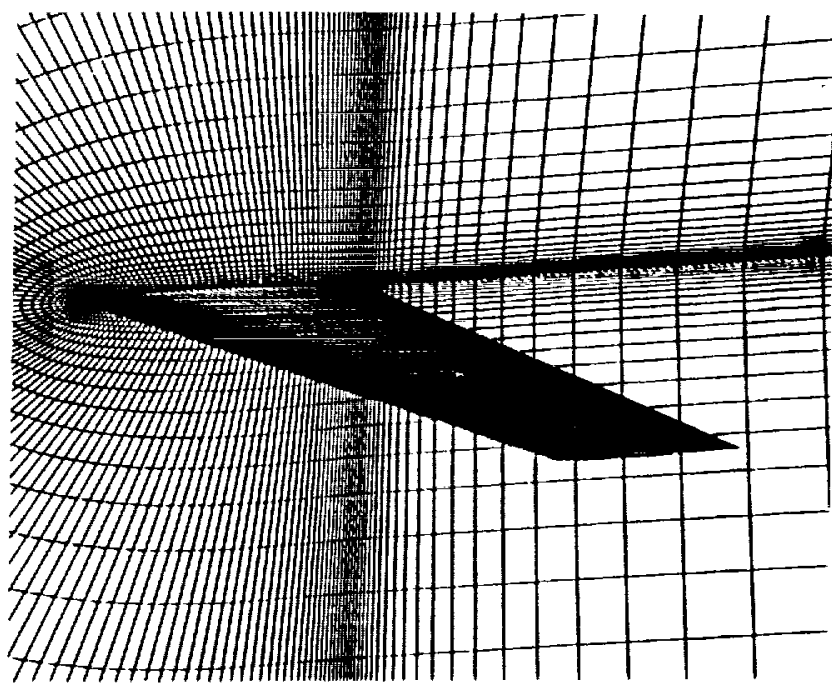

Figure 15. Partial view of computational grid on AGARD wing and symmetry plane.

\section{Aeroservothemoelasticity}

Because aerodynamic heating during high-speed flight through the atmosphere can destiffen the structure through changes in structural material properties and through material stress level changes caused by thermal gradients in built-up structural components, significant couplings between the elastic and rigid-body modes can result in lower flutter speeds, more pronounced aeroelastic response characteristics, and adverse aeroservoelastic (ASE) interactions. Work in aeroservothermoelasticity (ASTE) was initiated to achieve the following objectives: (1) enhance, develop, and apply codes for performing aeroservothermoelastic evaluations; (2) assess the effects of aerodynamic heating on the structural dynamic characteristics of a Demonstrator Vehicle and flight trajectory representative of the X-30; (3) conduct aeroelastic and ASE analyses using a representative flight control system; and, (4) define active control concepts that could be used to alleviate undesirable structural response or prevent aeroelastic instabilities. The first three tasks have been completed and are briefly described in this paper. More detailed descriptions of these activities are available in references 16 and 18.

Aeroelastic analyses. Aeroelastic characteristics of the Demonstrator Vehicle were predicted for a variety of configurations and flight conditions. Symmetric and antisymmetric aeroelastic equations of motion for the unheated vehicle were developed. Matched point flutter analyses were performed using conventional state-of-the-art subsonic, supersonic, and hypersonic linear unsteady aerodynamic theories which were described above. Results of the flutter analyses for the unheated vehicle are presented in references 2 and 18.

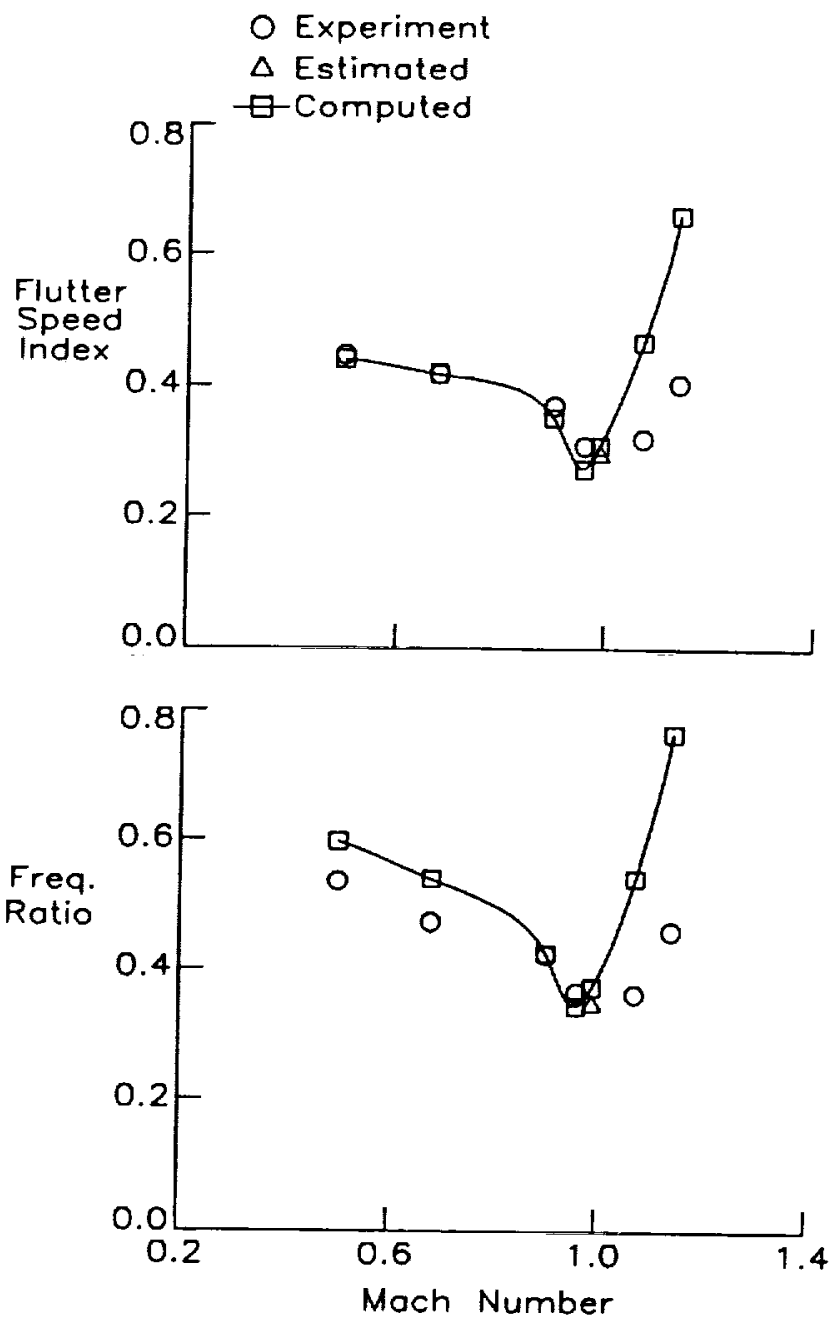

Figure 16. Flutter speed index and frequency ratio versus Mach number for AGARD wing.

For the symmetric flutter analyses, three types of instabilities were predicted within the Mach range from 0 to 25. The boundaries of these instabilities for the unheated Demonstrator Vehicle are shown in figure 17 for Mach numbers to 10 . The first instability is an unstable short period mode. The second instability is a bodyfreedom-flutter mode predicted to occur at high subsonic and supersonic speeds. This instability involves a coalescence of the vehicle short period and the wing pivot modes. The third instability is a flutter mode which is the coalescence of the wing pivot mode with the first fuselage bending mode. For the antisymmetric flutter analyses on the unheated vehicle, similar types of instabilities were predicted as found for the unheated symmetric case. Additional details of these analyses can be found in reference 18.

Thermal effects. The NASP vehicle is expected to reach extremely high temperatures as a result of 
aerodynamic heating. Because of the long duration of these high temperature conditions during ascent or descent trajectories, heat soaking of the primary structural components may be a problem. These temperatures are of concern for aeroelastic stability because load bearing components may encounter substantial structural changes. There are large areas of the vehicle that are expected to have little or no thermal protection and may experience large thermal gradients in the structure that could translate into adverse thermal loads. These loads may have an adverse impact on the vehicle trim, flutter, and flight control characteristics. Because of these considerations, an ASTE analysis procedure was developed and applied to the Demonstrator Vehicle. The results of the study are presented in reference 18 .

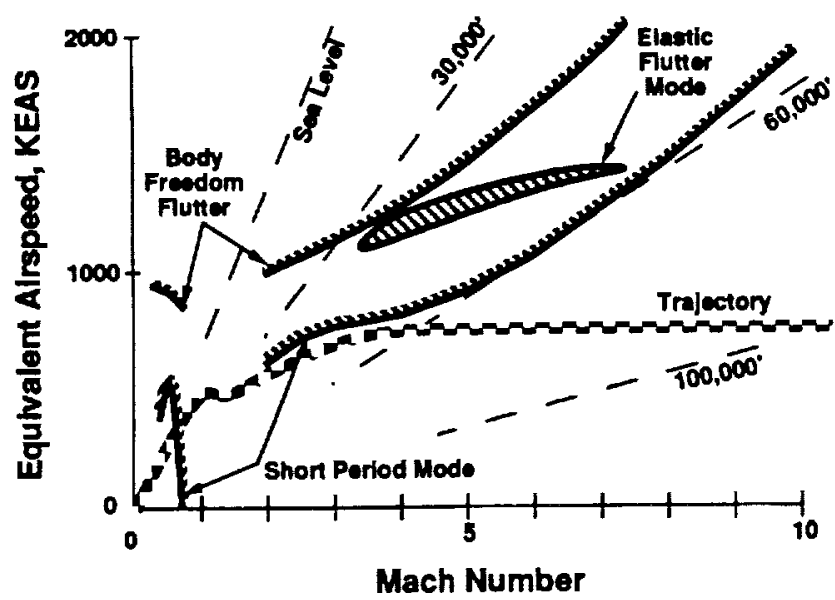

Figure 17. Symmetric aeroelastic stability characteristics of unheated Demonstrator Vehicle.

The procedure basically involves four steps. First, the vehicle's surface temperatures are calculated at various hypersonic flight conditions at the centers of the aerodynamic panels using the APAS code ${ }^{19}$. Next, an interpolation procedure is used to map the temperatures to the dynamics finite element model node locations and element centers. An element property interpolator outputs material properties for each element based on the elemental temperatures and tables of material properties as functions of temperature. For reasons described in reference 18, only the effects of material property changes were included in developing the stiffness matrices of the heated vehicle. The third step involves performing vibration analyses on the heated structure to obtain the modified modal characteristics. With the heated equations of motion available, the last step involves conducting unsteady aerodynamic, aeroelastic, and active control system analyses. The instability mechanisms of the analyses of the heated vehicle (not shown in figure 17) are similar to those of the unheated vehicle. However, there is some degradation in the stability margins. The details of the heated analyses are described in reference 18 .

Control system effects. A first-order state-space model of the vehicle was developed to study the interaction between the flexible structure and a pitch rate flight control system. To obtain the ASE model, the symmetric openloop aeroelastic model was modified to include an allmoveable wing control mode. Eight pairs of acceleration and pitch rate gyros were selected as the sensing devices. These sensors were judiciously placed along the fuselage near the nose, the pilot station, the vehicle center-ofgravity position, the wing pivot (spindle), and the tail stations, and near the wing root, mid span, and wing tip stations. A baseline pitch rate control system consisting of proportional and rate feedback was also included in the first-order ASE model. As described above, the vehicle flight dynamics are characterized by an unstable dead-beat (zero frequency) short period mode throughout most of the flight envelope; in terms of its aeroelastic characteristics, the structural modes were predicted to be stable within the flight envelope.

Closed-loop analyses were performed to assess the effects of the baseline controller on the unheated and heated ASE models at several points along the ascent trajectory. This controller was found to be very effective in stabilizing the unstable short period mode when the vehicle was assumed to be rigid. However, the baseline controller was inherently unstable throughout the flight trajectory when flexible modes were added. The controller-commanded motion of the massive all-moveable wing imparts a "ringing" motion throughout the entire structure. This ringing motion of the structure when improperly phased by the controller is the cause of the instability. A design of an LQG-based (linear quadratic regulator theory), reducedorder, flight control system was able to stabilize the unstable short period mode in the presence of flexible aircraft modes.

It can be concluded that adverse ASE interactions are highly probable if the design of flight control systems for NASP-like vehicles doesn't take into account the highly flexible fuselage characteristics and if it is not sufficiently robust to account for changes in fuel usage and changes in structural vibration modes due to aerodynamic heating.

\section{Experimental Investigations}

Several laboratory and wind-tunnel experiments were planned to determine and understand the aeroelastic behavior of the Demonstrator Vehicle. Test data were obtained for correlation and validation of the analytical codes and methods used during the design of the vehicle. Aeroelastic models of fuselage panels, lifting surfaces and complete vehicle designs were developed and tested. These experiments are described in this section and selected results are presented.

\section{Panel flutter}

Because of the requirement for a minimum weight structure which must cope with severe thermal environments, prevention of panel flutter is another problem designers must face. The objectives of this effort are to develop a test fixture for flutter assessment in the 
supersonic speed regime and to provide experimental data for analytical correlation. To accomplish these objectives a splitter plate/fixture was designed and built for the NASA Langley Unitary Plan Wind Tunnel ${ }^{20}$. The test panels were designed to flutter in Section 1 of this tunnel (Mach number 1.46 to 2.86 ).

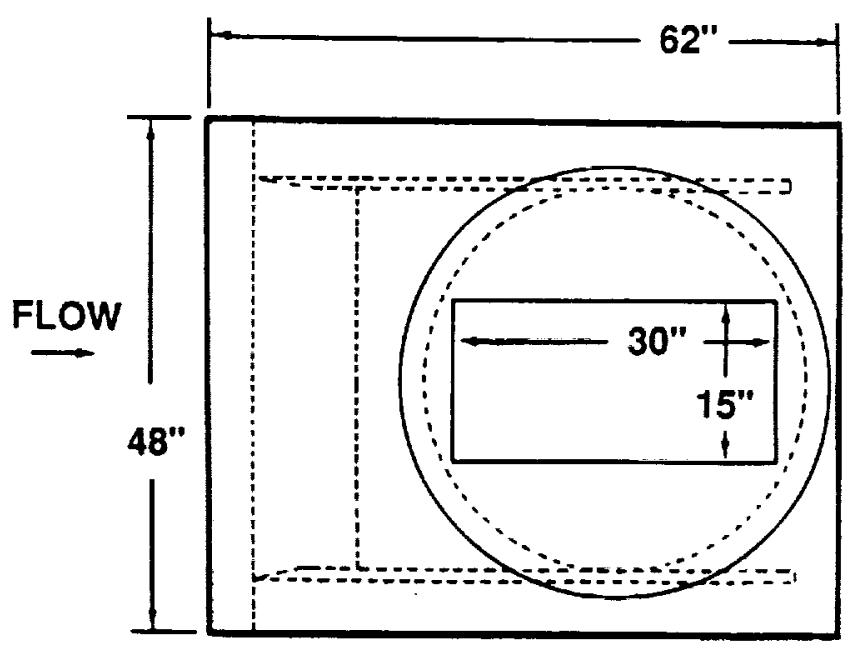

Figure 18. Front view drawing of panel flutter model test fixture.

The test configuration consists of a splitter plate/fixture and test panel. Figure 18 shows the front view (looking across the tunnel) of the model with the overall dimensions. A circular piece, called the "yaw table," is shown in the figure. The yaw table holds the test panels of dimensions 15 in by 30 in. The yaw table can be manually set at several different yaw angles to test different flow angularities without affecting the panel edge conditions. The test panel is mounted in a frame that simulates fixed edge conditions; however, these edge supports can be adjusted (unclamped and reclamped) to relieve inplane stresses due to temperature changes. This clamping mechanism and a separate system for applying in-plane loads are contained in the cavity behind the yaw table. The cavity also contains a pressure control system for changing the pressure across the panel.

To protect the panel during start-up and shutdown of the tunnel, a waffle-like support located in the cavity is positioned against the test panel and a low pressure is maintained in the cavity. This support system can be seen in the photograph in figure 19.

Three types of panels were fabricated and tested in the wind tunnel. The first panel is a "rigid" panel instrumented to measure the static pressure distribution. The two flexible panels are instrumented with accelerometers, thermocouples, and strain gauges. One of the flexible panels is a constant thickness (.05") aluminum panel. The other flexible panel shown in figure 20 is an orthotropic or stiffened aluminum panel (.016" upper panel bonded to $.050^{\prime \prime}$ slotted lower panel).

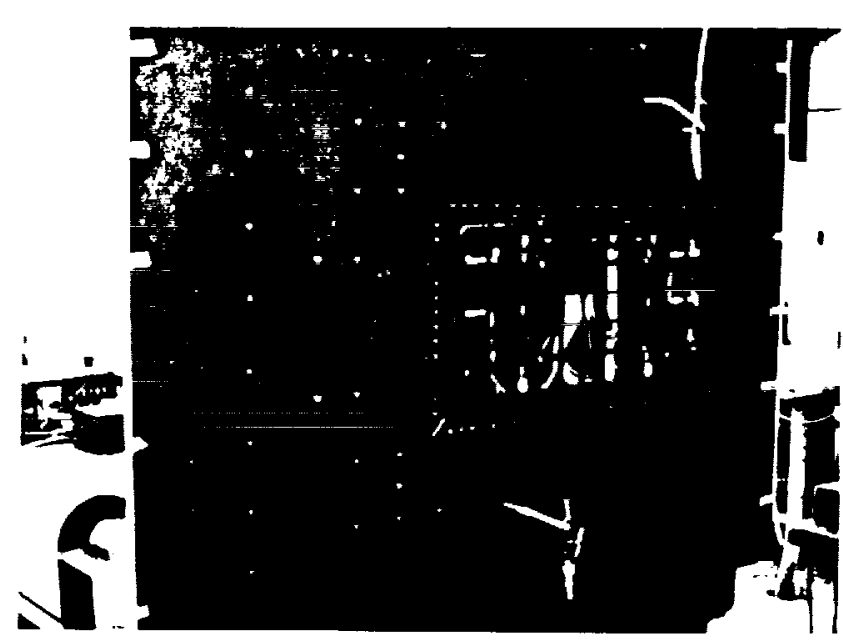

Figure 19. Photograph of test panel support system.

The flexible panels were modeled analytically using the NASTRAN ${ }^{21}$ and EAL 22 finite element code to obtain frequencies and mode shapes. For flutter predictions, the panel flutter criteria described in references 23 and 24 were used along with predictions from linear supersonic and piston theory methods. In figure 21 , predicted flutter boundaries are plotted on the wind tunnel operating envelope. These piston theory predictions are for the orthotropic panel at $0^{\circ}$ flow angularity (length/width $=$ 2.0) and for $90^{\circ}$ (length/width $=0.5$ ). This panel becomes more flutter critical as the flow angularity increases. Additional analytical results and the associated test data will be presented in a future paper.

\section{Lifting surface aeroelasticity}

Component models of the lifting surfaces on the Demonstrator Vehicle were developed to investigate their aeroelastic behavior. They include all-moveable wings and a vertical fin with a relatively large rudder. The wing models were developed for testing at subsonic to hypersonic speeds. The fin model is being developed for testing at subsonic and transonic speeds.

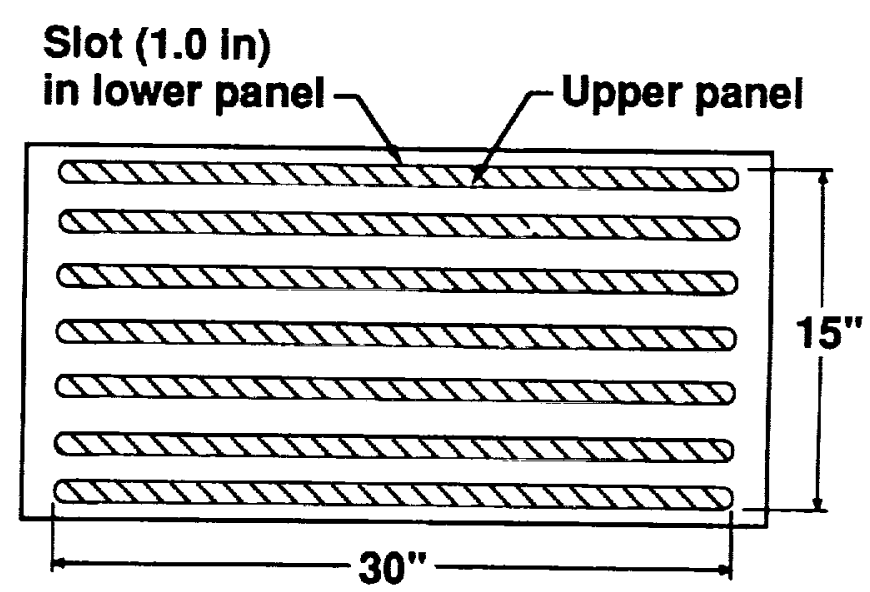

Figure 20. Front view drawing of the orthotropic panel. 


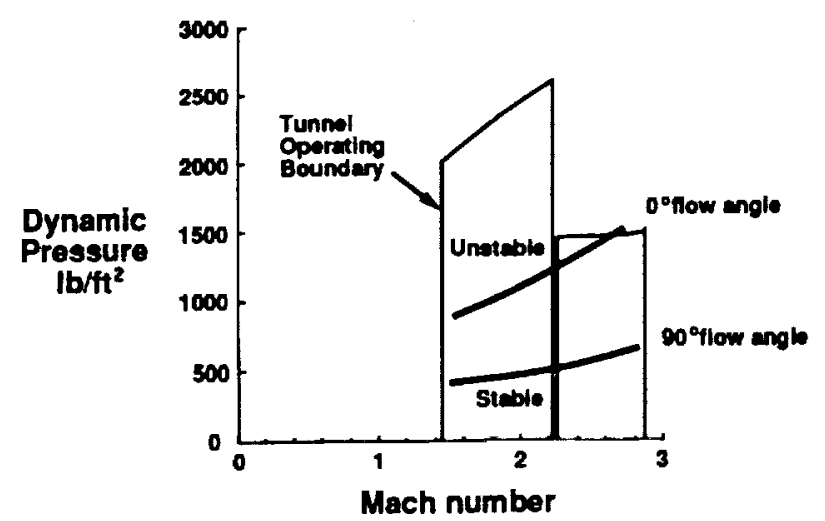

Figure 21. Predicted flutter boundaries for the orthotropic panel model.

The all-moveable wing models are pictured in figure 22. These models were designed for testing in the following wind-tunnels which are located at NASA Langley Research Center: the Transonic Dynamics Tunnel (TDT), the supersonic Unitary Plan Wind Tunnel (UPWT) and the Hypersonic Helium Tunnel (HHT). The transonic and supersonic models are mounted on splitter plates which are positioned outside of the tunnel sidewall boundary layer. The hypersonic model is mounted on a body of revolution and strut which are injected into the tunnel after the starting shock has passed through the test section.

Typically the wing models experience a static divergence instability which is influenced by the flexibilities of the pitch actuator and the wing structure forward of the pitch axis. Some results of the supersonic test $^{25}$ in the UPWT are shown figure 23. Subcritical response data show that the wing pitch frequency decreases as the dynamic pressure is increased. At the divergence condition, this frequency is zero.

In addition to static divergence data, it is desirable to acquire flutter data for these all-moveable wings. For the hypersonic wing test, a mass will be added to the trailing edge of the model. Analytical pretest flutter predictions 26 for this model are shown in figure 24 . The results show that the addition of mass and the reduction of pivot stiffness both have adverse effects on the flutter stability.

\section{Vehicle flutter}

To investigate the transonic aeroelastic behavior of the complete vehicle, a full-span model of the Demonstrator Vehicle was developed for testing in the TDT. The model is pictured in figure 25 . The fuselage is approximately 15 feet in length and is attached to a pedestal support system which allows both pitching and plunging motions. The model has all-moveable wings (6foot span) and twin vertical fins. The dynamic characteristics of the baseline model are similar to those of the Demonstrator Vehicle. Model parameters which were varied during the tests include wing pitch actuator stiffness, wing pitch axis location and fuselage shape. Some results from the tests 27 are shown in figure 26. The instability shown here is a coupling of the wing pitch mode and fuselage bending mode. The boundary shows

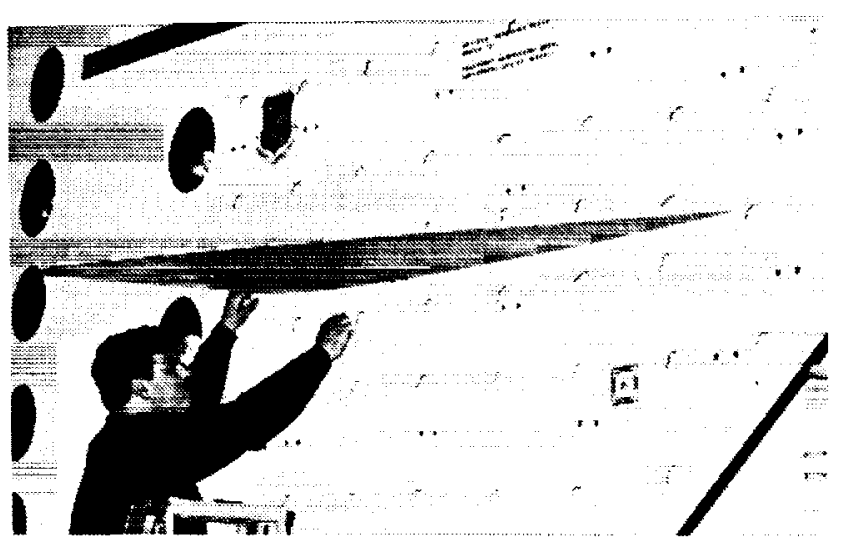

(a) Transonic model for TDT.

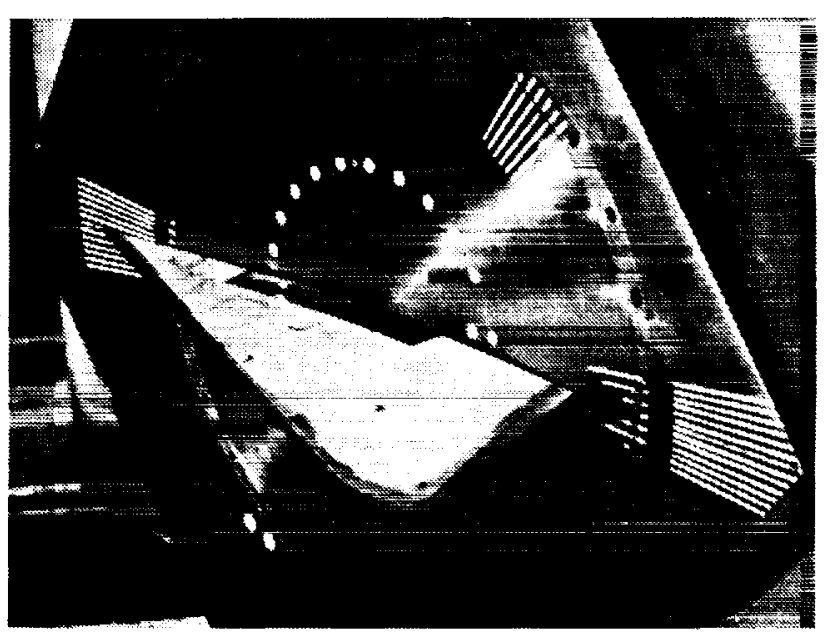

(b) Supersonic model for UPWT.

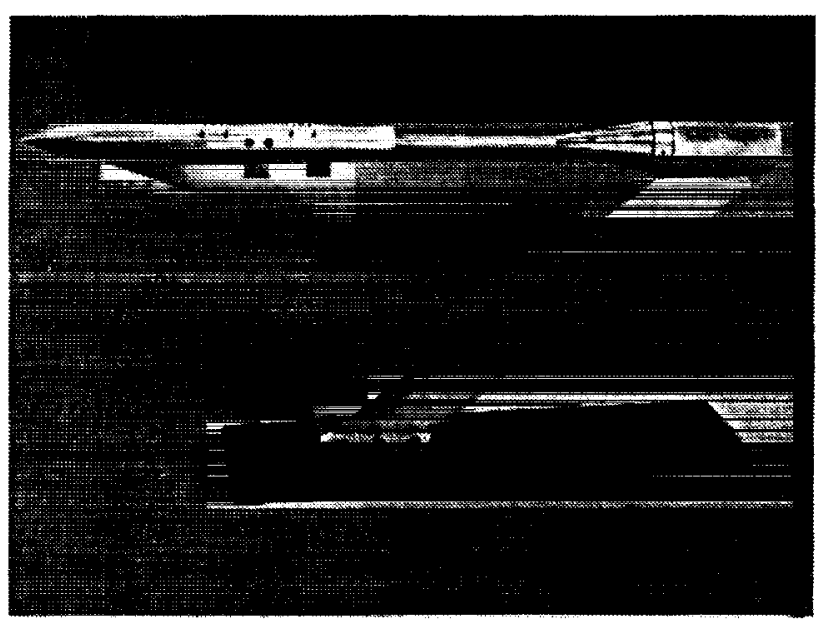

(c) Hypersonic model HHT.

Figure 22. All-moveable wing aeroelastic models. 


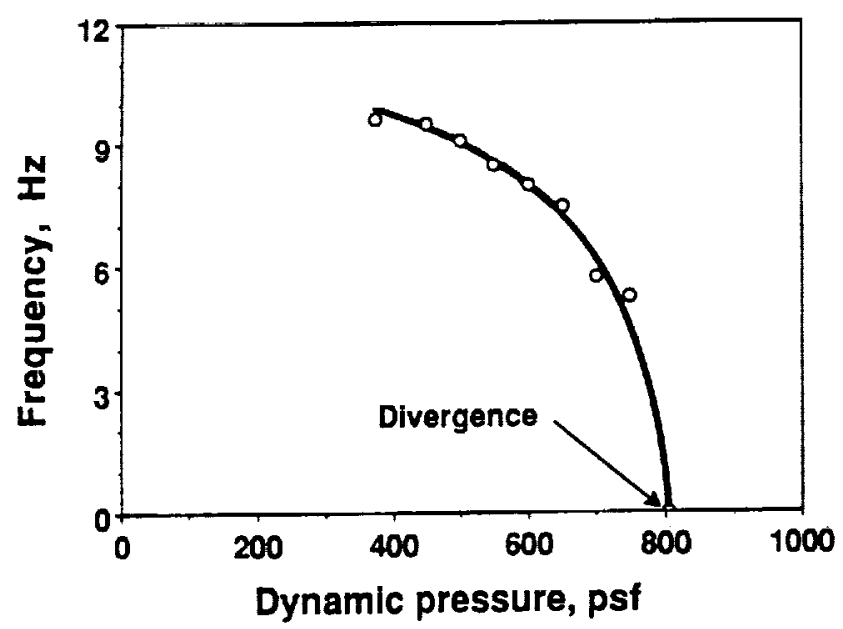

Figure 23. Static divergence results from wing model test in supersonic UPWT.

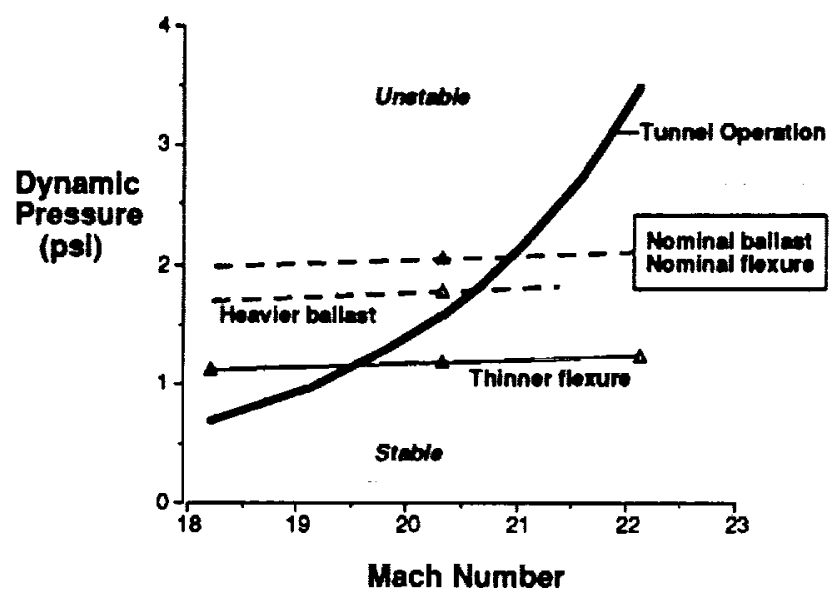

Figure 24. Flutter analysis results for the HHT wing model.

a substantial dip in the transonic region which is similar to that predicted for the vehicle. Additional test results and comparisons with analyses are presented in reference 27.

\section{Summary}

Several aeroelastic studies were conducted in direct support of the development of the NASP X-30 vehicle by the national contractor team. These studies were conducted by the NASA and the Wright Laboratory using a Demonstrator Vehicle as the baseline. This research includes the development of computational codes for predicting unsteady aerodynamic pressures, analyses to determine the aerodynamic heating effects on vehicle aeroelasticity and analyses to determine the effects of fuselage flexibility on the stability of the flight control systems. Furthermore, several scale models

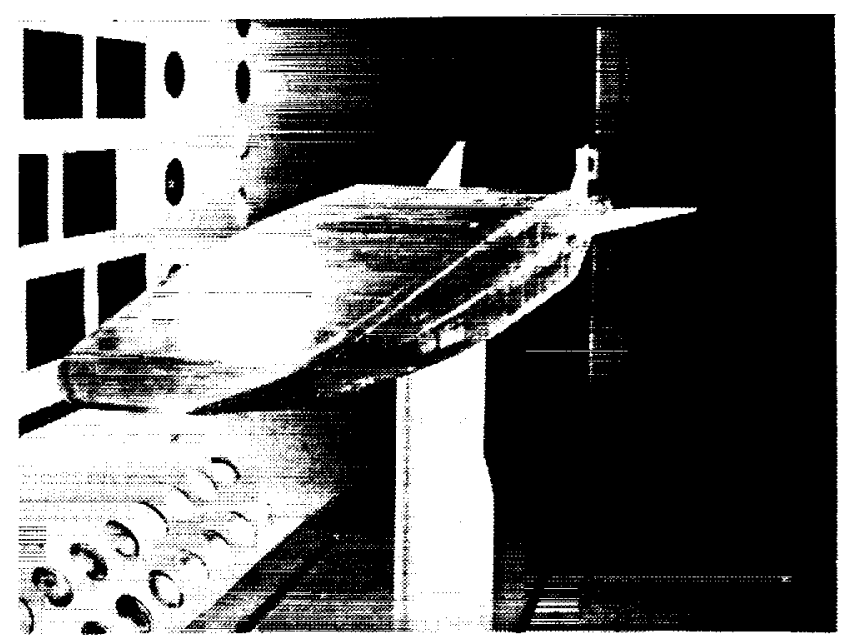

Figure 25. Photograph of flexible-fuselage model in TDT.

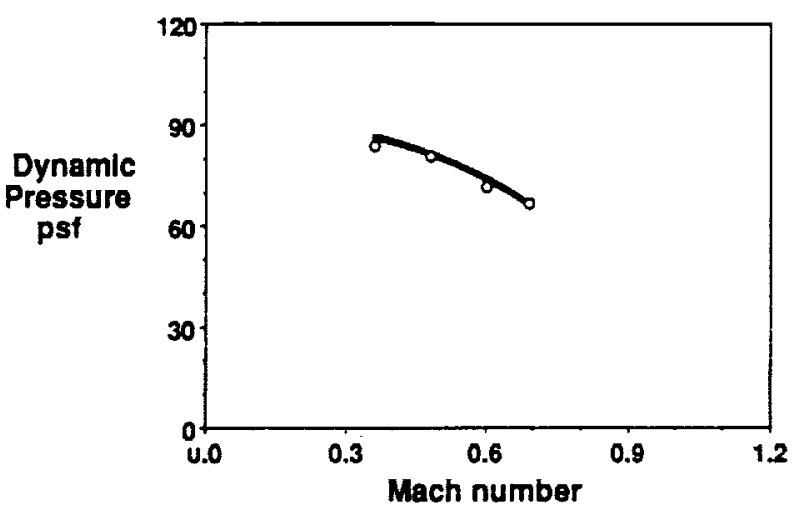

Figure 26. Flutter test results of flexible-fuselage model.

were developed and wind-tunnel tested across the Mach number range to better understand the aeroelastic behavior of the X-30 and to obtain data for code validation and correlation.

\section{References}

1. Doggett, Roben V., Jr; Ricketts, Rodney H.; Noll, T. E.: and Malone, John B.: NASP Aeroservothermoelasticity Studies. NASA TM 104058, April 1991.

2. Spain, C. V.; Zeiler, T. A.; Gibbons, M. D.; Soistmann, D. L.; and Pozefsky, P.: Aeroelastic Character of a National Aero-Space Plane Demonstrator Concept. Presented at the AIAA 34th Structures, Structural Dynamics, and Materials Conference, La Jolla, CA, April 1993. AIAA Paper No. 93-1315.

3. Pototzky, T.; Zeiler, T.; Noll, T.; Whitlow, W.; Heeg, J.; and Scott, R.: Aeroservothermoelasticity, An Interim Review of NASP GWP No. 75. NASP Contractor Report 1135, August 1992. 
4. Cunningham, H. J.; Batina, J. T.; and Bennett, R. M.: Modern Wing Flutter Analysis by Computational Fluid Dynamics Methods. Lournal of Aircraft, Vol. 25, No. 10, pp. 962-968, October 1988.

5. Silva, W. A.; and Bennett, R. M.: Using Transonic Small Disturbance Theory for Predicting the Aeroelastic Stability of a Flexible Wind-Tunnel Model. AIAA Paper 90-1033, April 1990.

6. Batina, J. T.; Seidel, D. A.; Bland, S. R.; and Bennett, R. M.: Unsteady Transonic Flow Calculations for Realistic Aircraft Configurations. Lournal of Aircraft. Vol. 26, No. 1, pp. 21-28, January 1989.

7. Giesing, J. P.; Kalman, T. P.; and Rodden, W. P.: Subsonic Unsteady Aerodynamics for General Configurations, Part 1, Volume 1 - Direct Application of the Nonplanar Doublet-Lattice Method. AFFDL-TR-71-R, Part 1, Volume 1, 1971.

8. Peele, E. L.; and Adams, W. M.: A Digital Program for Calculating the Interaction Between Flexible Structures, Unsteady Aerodynamics and Active Controls. NASA TM-80040, January 1979.

9. Swihart, J. M.; and Whitcomb, C. F.: Pressure Distributions on Three Bodies of Revolution to Determine the Effect of Reynolds Number up to and Including the Transonic Speed Range, NASA RM L53H04, October 1953.

10. Anderson, W. K.; Thomas, J. L.; and Rumsey, C. L.: Extension and Applications of Flux-Vector Splitting to Unsteady Calculations on Dynamic Meshes. AIAA Paper 87-1152, June 1987.

11. Batina, J. T.: Unsteady Euler Algorithm With Unstructured Dynamic Mesh for Complex-Aircraft Aeroelastic Analysis. AIAA Paper 89-1189, April 1989.

12. Robinson, B. A.; Batina, J. T.; and Yang, H. T. Y.: Aeroelastic Analysis of Wings Using the Euler Equations with a Deforming Mesh. Journal of Aircrafl, Vol. 28, No. 11 , pp. 778-788, November 1991 .

13. Bennett, R. M.; and Desmarais, R. N.: Curve Fitting of Aeroelastic Transient Response Data with Exponential Functions, Flutter Testing Techniques. NASA SP-415, May 1975.

14. Yates, E. C., Jr.; Land, N. S.; and Foughner, J. T., Jr.: Measured and Calculated Subsonic and Transonic Flutter Characteristics of a $45^{\circ}$ Sweptback Wing Planform in Air and in Freon-12 in the Langley Transonic Dynamics Tunnel. NASA TN D-1616, March 1963.

15. Lee-Rausch, E. M.; and Batina, J. T.: Wing Flutter Boundary Prediction Using Unsteady Euler Aerodynamic Method. Presented at the AIAA 34th Structures, Structural Dynamics, and Materials Conference, La Jolla, CA, April 1993. AIAA Paper 93-1422.
16. Scott, R.; and Pototzky, A.: A Method of Predicting Quasi-Steady Aerodynamics for Hypersonic Flutter Analysis Using Steady CFD Calculations. Presented at the AIAA 34th Structures, Structural Dynamics, and Materials Conference, La Jolla, CA, April 1993. AIAA Paper 93-1364.

17. Walters, R.; Reu, T.; McGrory, W.; Thomas, J.; and Richardson, P.: A Longitudinally-Patched Grid Approach with Applications to High Speed Flows. AIAA Paper No. 88-0715, January 1988.

18. Heeg, J.; Zeiler, T.; Pototzky, A.; Spain, V.; and Engelund, W.: Aerothermoelastic Analysis of a NASP Demonstrator Model. Presented at the AIAA 34th Structures, Structural Dynamics, and Materials Conference, La Jolla, CA, April 1993. AIAA Paper 93-1366.

19. Cruz, C.; and Wilhite, A.: Prediction of High Speed Aerodynamic Characteristics Using the Aerodynamic Preliminary Analysis System (APAS). Presented at the AIAA 7th Applied Aerodynamics Conference, Seattle, WA, July 1989. AIAA Paper No. 89-2173.

20. Jackson, C. M.; Corlett, W. A.; and Monta, W. J.: Description and Calibration of the Langley Unitary Plan Wind Tunnel. NASA TP 1905, 1981.

21. The NASTRAN User's Manual. NASA SP-222(07), June 1985.

22 Whetstone, W.: EISI-EAL Engineering Analysis Language Reference Manual. Engineering Information Systems, Inc., San Jose, CA, 1983.

23. Lemley, C. E.: Design Criteria for the Prediction and Prevention of Panel Flutter. AFFDL-TR-67-140, August 1968.

24. Laurenson, R. M.; and McPherson, J. L.: Design Procedures for Flutter-Free Surface Panels. NASA CR2801, March 1977.

25. Cole, S. R; Florance, J. R.; Thomason, L. B.; Spain, C. V.; and Bullock, E. P.: Supersonic Aeroelastic Instab-ility Results for a NASP-Like Wing Model. Presented at the AIAA 34th Structures, Structural Dynamics, and Materials Conference, La Jolla, CA, April 1993. AIAA Paper No. 93-1369.

26. Wynne, Eleanor C.: Structural Dynamics Division Research and Technology Accomplishments for FY 91 and Plans for FY 92. NASA TM 104188, January 1992.

27. Soistmann, David L.; and Spain, Charles V.: An Experimental and Analytical Study of a Lifting Body Wind-Tunnel Model Exhibiting Body Freedom Flutter. Presented at the AIAA 34th Structures, Structural Dynamics, and Materials Conference, La Jolla, CA, April 1993. AIAA Paper No. 93-1316. 


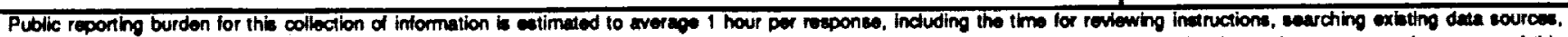
gathering and maintaining the data needed, and corrpleting and revlewing the collection of liformation. Send comments regarding this burden estimite of any other aspect of this

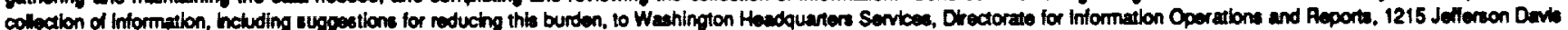

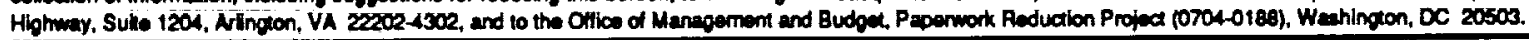

\begin{tabular}{|l|l|l|}
\hline 1. AGENCY USE ONLY (Lave blank) & $\begin{array}{l}\text { 2. AEPOAT DATE } \\
\text { March } 1993\end{array}$ & $\begin{array}{l}\text { 3. AEPORT TYPE AND DATES COVERED } \\
\text { Technical Memorandum }\end{array}$ \\
\hline
\end{tabular}

4. TITLE AND SUBTTLE
An Overview of Aeroelasticity Studies for the National Aero-Space Plane 5. FUNDING NUWBERS 763-23-41

6. AUTHOA(S)

Rodney H. Ricketts, Thomas E. Noll, Woodrow Whitlow, Lawrence J. Huttsell

7. PERFORLING ORGANIZATION NAME(SI AND ADDAESSES)

8. PERFORMING ORGAKIZATION

NASA Langley Research Center REPOFT NUMBER

Hampton, VA 23681-0001

9. SPONSOAINO / MONITORING AGENCY NAME(S) AND ADOAESS(ES)

National Aeronautics and Space Adminstration

Washington, DC 20546-0001

10. SPONSORING / WONITORING

ACENCY REPORT NUMBER

NASA TM-107728

\section{SUPPLEMENTARY NOTES}

Presented at the AlAA 34th SDM Conference

April 19-23, 1993

12a. DISTRIBUTION/AVAILABILTY STATEMENT

12b. DISTRIBUTION COOE

Unclassified-Unlimited

Subject Category 02

13. ABSTRACT (Maximum 200 words)

The National Aero-Space Plane (NASP), or X-30, is a single-stage-to-orbit vehicle that is designed to takeotf and land on conventional runways. Research in aeroelasticity was conducted by the NASA and the Wright Laboratory to support the design of a flight vehicle by the national contractor team. This research includes the development of new computational codes for predicting unsteady aerodynamic pressures. In addition, studies were conducted to determine the aerodynamic heating effects on vehicle aeroelasticity and to determine the effects of fuselage flexibility on the stability of the control systems. It also includes the testing of scale models to better understand the aeroelastic behavior of the $X-30$ and to obtain data for code validation and correlation. This paper presents an overview of the aeroelastic research which has been conducted to support the aiframe design.

\begin{tabular}{|c|c|c|c|c|}
\hline \multirow[t]{2}{*}{ 14. SUBJECT TERMS } & \multirow{2}{*}{\multicolumn{2}{|c|}{$\begin{array}{l}\text { Aero-Space Plane } \\
\text { Aeroelasticity } \\
\text { Unsteady Aerodynamics }\end{array}$}} & \multirow{2}{*}{$\begin{array}{l}\text { Panel Flutter } \\
\text { Aeroservoelasticity } \\
\text { Wind-Tunnel }\end{array}$} & $\begin{array}{l}\text { 15. NUMBER OF PAGES } \\
12\end{array}$ \\
\hline & & & & $\begin{array}{l}\text { 16. PRICE CODE } \\
\text { A03 }\end{array}$ \\
\hline \multicolumn{2}{|c|}{$\begin{array}{l}\text { 17. SECURITY CLASSIFICATION } \\
\text { OF REPOFT } \\
\text { Unclassified }\end{array}$} & $\begin{array}{l}\text { 16. SECUAITY CLASSIFICATION } \\
\text { OF THIS PAGE } \\
\text { Unclassified }\end{array}$ & $\begin{array}{l}\text { 19. SECUATY CLASSIFICATION } \\
\text { OF ABSTRACT }\end{array}$ & 20. UMTATION OF ABSTAACT \\
\hline
\end{tabular}

